\title{
TECHNOLOGY-ENRICHED SCHOOLS: CO-OPERATION BETWEEN TEACHERS AND RESEARCHERS
}

\author{
J. J. BeIShUizen ${ }^{1}$ and J. MoONEN ${ }^{2}$ \\ 'Department of Educational Psychology, Leiden University, Wassenaarseweg 52, NL-2333 AK Leiden \\ and ${ }^{2}$ Division of Educational Instrumentation, Faculty of Educational Science and Technology, \\ University of Twente, P.O. Box 217, 7500 AE Enschede. The Netherlands
}

\begin{abstract}
Technology-enriched schools offer unique opportunities for research into the use of information technology in education. As in every applied educational research project, some concerns should be carefully considered. One of them is teacher involvement. Another issue of concern is finding a proper balance between development and controlled research. In the Dutch Technology-Enriched School project three schools were equipped with exceptional hardware and teacher facilities. An implementation strategy of progressive broadening was applied. At the start of the project, a small number of interested teachers was invited to join the project. These avant-garde teachers based their enthusiasm primarily on the leading principle of the project: using information technology to improve the quality of education. Teachers and researchers closely collaborated to develop, implement and evaluate teaching units with the computer as an aid to teaching and learning. After some years of experience, in which examples of good practice were created, the project's scope was broadened to enable new teachers to join the project. Some of these teachers were perhaps less personally convinced of the value of the project's leading principle than the avant-garde teachers, but they were better able to evaluate costs and benefits. Finally, the implementation strategy of progressive broadening resulted in a change in attitudes of the teachers: they began to see themselves as active contributors and participators in the process of educational change.
\end{abstract}

\section{INTRODUCTION}

An increasing number of Technology Enriched-Schools (TESs) serve both as an environment for development of examples of innovative use of technology in education and a testbed for research into issues related to computers and education. A recent survey[1] provided an overview of nine projects throughout the world. The integration of development and research activities in a TES appears, at first glance, to have both advantages and disadvantages. The advantages have to do with the ecological validity of research activities in a real school setting. Also, the comprehensive character of a TES research project creates unique opportunities for studying interactions between different levels of educational change: the school level, including school-wide use of information technology for management and administration purposes; the curriculum level; and the classroom level. Development of applications of information technology in a TES may profit from the existence of a rich infrastructure and experienced teachers and students, and may be inspired by the exchange of ideas and experiences between teachers and supporting staff. Some issues of concern are related to both the development and implementation interests and the research interests of the project. As far as development and implementation are concerned, teacher involvement is a predominant precondition for success [2]. With respect to the research aims of a TES project the dilemma of development versus controlled research is often encountered[3]. These issues will be further explored in the next sections.

\section{TEACHER INVOLVEMENT}

Teachers are the cornerstone of every innovation in education, as has been acknowledged by many authors, for example[1,4]. As they are the responsible agents in the classroom all teaching and learning activities should be supported by their full consent. Are teachers willing to change as part of a TES project? Fullan [5] distinguished four types of teachers [5, p.127]:

(1) The autonomous teachers want to decide for themselves whether a change meets personal demands and should therefore be adopted.

(2) The developers/participators really advocate a curriculum change and are prepared to play an active role in making decisions and developing new materials. 
(3) The receivers do not personally invest time or effort in a process of change but are interested in using new materials.

(4) The interactors want to share experiences with new curriculum materials with colleagues also involved and outside experts, but complain about lack of time, lack of administrative support or lack of opportunities to change experiences.

In a TES project, it is important to increase the number of the second type of teachers. These teachers should build up enough innovative momentum to convince other teachers that the process of change is valuable.

How can the interest of teachers be caught? Fullan [5] emphasized that three questions are often used as a criterion for readiness to accept new plans:

(1) Is a need addressed by the plan? Will students profit from the intended changes in education?

(2) Is the plan clear in terms of action to be taken by the teachers?

(3) What are the personal costs and benefits in terms of time, efforts, new skills and competences to be acquired?[5, p. 113].

If a plan for change is clear with respect to the first two criteria and provides a positive balance of personal costs and benefits, then teachers might consider to embark on it. If an innovative plan is forced into a school system without meeting the three conditions, then some implementation problems can be easily foreseen. Later, we will explain how we dealt with the problem of teacher involvement in the Dutch TES project.

\section{DEVELOPMENT VERSUS CONTROLLED RESEARCH}

In a TES, experiments cannot be planned in the usual top-down way. Integration of experimental teaching units, both in content and in method, in the existing curriculum is an important precondition for success[6]. This implies that the teachers involved should fully endorse the experiments. In fact they bear the responsibility for everything going on in their classrooms. Therefore, a top-down research approach, with the researcher as the sole person responsible, is not appropriate. Instead, experimental teaching units should be developed in cooperation by teachers, subject-matter experts and researchers together $[2,7,8]$. Research and development are closely interrelated in a TES. The research team is engaged both in evaluating the impact of the use of information technology in education and designing and optimizing learning environments in which the computers play a supporting role. A technology-enriched school cannot be considered a model school, which can casily be copied in other secondary school situations. The favourable conditions in a TES in terms of available hardware and other resources, are usually not existent in ordinary schools. Moreover, both failures and successes are valuable sources of information in a technologyenriched school. In order to study factors which contribute to success and failures in implementing computers in education some form of controlled comparison is necessary, either between conditions with and without computer support, or between situations before and after the introduction of computers. However, the experimental-model characteristic is not completely absent in a technology-enriched school. In order to study changes at the curriculum and school level it is a necessary precondition to bring about effective changes at the classroom level. Teachers need to experience that computers are valuable tools to improve educational practice. Without success stories changes in curricula or attitudes of teachers cannot be expected. Therefore, the research policy of a technology-enriched school project should not only be aimed at a careful analysis of factors contributing to success and failure, but, at the same time, include an active and encouraging approach towards teachers, in order to secure that the available resources are appropriately used and that, eventually, potentials and drawbacks of computers in education can be assessed on the basis of a substantial amount of hands-on experience.

\section{THE DUTCH TES PROJECT}

The background, goals, and context of the Dutch TES project have been explained elsewhere [9]. Here, some essential characteristics will be briefly outlined. Within the context of broad-scale 
introduction of computers in secondary education, the Dutch government started in 1987 a $5-y r$ TES project aimed at the investigation of the impact of a technology-enriched school environment on the school as a whole: its administrative and teaching levels. Four major questions were the focus of the Dutch TES project. What are the effects of a TES environment on:

(1) The organization and the administration of the school, automation of aspects of administration and management, attitudes of teachers and administration with respect to their educational and managerial tasks, and school policy?

(2) The curricula: changes in content, integration of subject areas, changes in time spent on specific subject areas?

(3) The roles and opinions of teachers with respect to the content of a subject area, didactical approaches, possibilities and limitations of computer use? and

(4) The teaching-learning process, e.g. new forms of cooperative learning?

Two subprojects were defined. In Project East, the University of Twente Department of Education collaborated with two regional general secondary schools with 1400 and 900 students, 92 and 68 staff, respectively. In Project West, the University of Leiden Department of Educational Psychology and the University of Utrecht Department of Mathematics Education collaborated with one suburban secondary school (with 1500 students and 90 staff). The age range of the students involved was 12-18 years. All schools prepare students to enter university or other types of education.

In each of the schools, extra budget for personnel was used to support two kinds of activities: (a) to create new part-time functions to be executed by teachers already on the school staffs, computer coordinator, system manager, computer lab manager, and (b) to pay for released time for teachers to enable them to explore the potentials of the computer in their subject area, to prepare, carry out and evaluate experimental lessons with the computer, and to gain the interest of fellow teachers within their departments.

In all three schools, computers were primarily made available in computer labs. All computers had MS-DOS as their operating system. The schools in the East purchased AT-type machines. At the West school XT-type computers were located in two computer labs with 16 systems in each lab, and in the office of administration. Most of the computers were networked, some of the computers were put on mobile platforms. Each school provided the teachers' room with computers to support the preparation of the lessons. Other rooms such as the library, administrative offices, and the vice-principals' offices had computers. Many laser printers, scanners, LCD screens for overhead projection, and CD-ROM players were made available.

An extensive teacher support system was created in each of the schools, consisting of the following eight facilities:

(1) In-service training. Most courses were internally organized under the responsibility of the school computer co-ordinators. Initially, they were specifically organized around using general system and applications software: MS-DOS, word processing, databases, and spreadsheets. Courses to support instructional computing were also started. As using computers in schools affected administrative personnel-through the use of word processing, desktop publishing, automated handling of student grades, and registering absenteeism-there was a growing need to train the administrative personnel as well. The system managers followed some external courses on networking and school-management systems in order to cope with those problems.

(2) Released-time. This varied within the schools, but for many teachers it was approx. $2 \mathrm{~h}$ each week.

(3) Counselling by co-ordinators and a system manager. Advice was given on technical matters (operation of hardware and software and installation of software), and educational issues. Apart from this, the value of informal, moral support was also emphasized.

(4) Sharing of experiences between teachers in a department. An effort was made to assign two teachers in each participating department to the project (see also the section on implementation strategy). This decision was motivated by the consideration that mutual domainoriented, pedagogical, and moral inspiration should facilitate the development of more 
successful computer applications than might occur through the efforts of separate teachers $[2,10]$.

(5) The research and production team. In many departments teams were formed, consisting of the teachers with released-time hours, a school computer co-ordinator, a researcher, and in some instances a subject-matter specialist, to develop instructional materials, accompany the teachers during the implementation of the new materials, and evaluate the outcomes.

(6) Information. Special efforts were made to supply teachers with additional information, such as periodicals, announcements, demos, and new software.

(7) Computers and work space. Extra sets of computers were available for teachers' use. Mobile sets were located in several wings of the schools to be used for demonstration purposes in the classroom and for teacher preparation.

(8) Computers for private use at home. Special measures were worked out, with certain financial and tax benefits, stimulating teachers to buy computers for their private use at home. The idea was that they would use their personal computers also to support school activities such as reviewing courseware and preparing lessons.

\section{THE PROGRESSIVE BROADENING IMPLEMENTATION STRATEGY}

The issues of teacher involvement and finding a proper balance between development and controlled research were introduced before as issues of concern in a TES project. How did we negotiate with these problems in the Dutch TES project? To answer this question the overall implementation strategy of progressive broadening adopted in one of the schools, the West school, will be set forth.

Implementing computers in education is an innovation process with two mutually dependent characteristics: the size of the effort and the stage of concern of the participants[11]. Moonen[12] has argued that integration of computers in secondary education should proceed along two parallel lines: a depth approach for a restricted number of departments and breadth approach for the remaining departments. The rationale behind this suggestion is the intention to provide as many facilities as possible for all departments. Since costs reduce possibilities, only a small number of departments can usually be equipped with a necessary minimum of facilities. Therefore, all departments should be encouraged to become acquainted with the possibilities of information technology by making use of general application software, and a small but growing number of departments is provided with more intensive support.

The second characteristic of the innovation process is the stage of concern of the participants, which determines their commitment. Van den Berg and Vandenberghe[13] describe seven stages of commitment relevant to the process of educational innovation. Moving from the level of no or small interest the personal involvement of teachers gradually increases along with their experience with renewed educational practice. Teachers begin to consider the possible impact of the innovation on the students. They identify tasks which should be carried out to realize the innovative efforts. They seek the co-operation of fellow teachers and, eventually, critically reflect on the renewed educational practice which may lead to further changes[11].

In one of the schools of the Dutch TES project (the West school) it was decided to adopt a strategy of gradual implementation, in which the initial depth-first approach would be slowly transformed into a breadth-first approach. This strategy was in fact the result of the decision at the very start of the project to focus on classroom experiences as soon as possible and. subsequently, the continuous analysis of ongoing activities throughout the school. In this section, the resulting progressive broadening strategy will be described in three stages: (a) the depth-first period, (b) the shifting from depth-first to breadth-first, and (c) the breadth-first period.

\section{The depth-first period}

At the start of the project it was decided to invite two teachers per department to join the project, in order to enable teachers to exchange ideas and critically discuss any proposals from the co-ordinators and/or the research team. Secondly, it was decided to substantially reduce the teaching burden of the participating teachers to provide them with enough time for orientation, in-service training and planning of computer-related activities in the classroom. This implied that 
a minimum number of 3 released hours per teacher had to be available. Thirdly, extra support by subject-matter specialists was considered necessary to supply the teachers with examples and ideas, and to support them during the process of planning, preparation, implementation and evaluation of experimental lessons in which the computer was used as a tool by both teachers and students. Fourthly, it was decided to refrain from developing new software. Only existing software would be used and integrated in classroom activities.

Taking the project's budget into account, no more than 10 teachers of five departments could be equipped with released time and subject-matter expertise. In each of the five departments a research and production team was formed, consisting of the two teachers, a subject-matter specialist (hired on the basis of 1 day per week during the project's second school year), a researcher and one of the co-ordinators. These research and production teams started to explore the existing available software, chose software to be tried out in the classroom, planned experimental lessons, developed accompanying materials (worksheets for students and teachers), supported the teachers during the implementation stage, made classroom observations and collected other relevant data, and evaluated the results.

During the development of experimental lessons with the computer as an aid, the researchers assisted by collecting relevant information, evaluating the software with the teachers, planning the actual lessons and developing accompanying materials for students (worksheets) and teachers (directions). When a subject-matter specialist was added to the team, some of these preparations were delegated to the expert. At the start of the lesson preparations the researcher identified the intentions and expectations of the teachers with regard to the experimental lessons. Expectations were recorded and noted for later use. During the lessons, the researchers observed the activities of teachers and students in the classroom. Afterwards the results were discussed in the team on the basis of the observations of the teachers and researchers, and the intentions and expectations as expressed by the teachers before the start of the lessons. These evaluations usually led to a second cycle of preparation, implementation and evaluation. As explained, sometimes comparisons were made with more traditional instruction of the same subject-matter. Eventually, the experiences were presented in papers, annual project reports, booklets for teachers in the same discipline, and meetings outside the school to inform unexperienced colleagues[14-17].

In some of the departments, the teams of teachers, researchers and subject-matter experts met weekly and put the results of the meetings on paper. Generally, this discipline of regular and frequent meetings was relaxed in the course of the project. As the teachers began to accumulate expertise the need for continuous support became less urgent. This enabled the researchers to shift their attention from collaborating in the design and implementation process to evaluating results, both in terms of learning outcome and teaching and learning processes, and presenting experiences and conclusions.

\section{The shift from depth-first to breadth-first}

In the course of the third year of the project, when six departments were actively participating, all teachers throughout the school were asked to fill out a questionnaire in order to find out the attitudes of teachers towards the use of computers in general. The items were developed and validated by Bouman et al.[18]. Table 1 provides the attitude data of the West teachers and the remaining teachers at the West school.

Table 1 shows that in 1989, the third project year, West teachers involved in the project had a more positive attitude towards computers than the remaining teachers for 1989. The differences are significant $(F=32.4, P<0.01)$ and remain significant after partialling out differences in

Table 1. Comparison of project and non-project teachers' attitudes towards computers during the 3 years of the project

\begin{tabular}{|c|c|c|c|c|c|c|c|c|c|}
\hline & \multicolumn{3}{|c|}{$\begin{array}{l}\text { Project } \\
\text { teachers }\end{array}$} & \multicolumn{3}{|c|}{$\begin{array}{c}\text { Non-project } \\
\text { teachers }\end{array}$} & \multicolumn{3}{|c|}{$\begin{array}{c}\text { All } \\
\text { teachers }\end{array}$} \\
\hline & $n$ & Mean & $\mathrm{SD}$ & $n$ & Mean & SD & $n$ & Mean & SD \\
\hline Questionnaire 1989 & 13 & 67.3 & 4.9 & 43 & 56.4 & 6.3 & 56 & 58.8 & 7.6 \\
\hline Questionnaire 1991 & 16 & 65.1 & 6.0 & 37 & 59.6 & 7.3 & 53 & 61.3 & 7.3 \\
\hline Questionnaire 1992 & 18 & 63.8 & 4.6 & 33 & 61.5 & 7.8 & 51 & 62.3 & 6.9 \\
\hline
\end{tabular}


number of years of experience between project teachers and non-project teachers $(F=21.9$, $P<0.01$ ).

In 1989 , the positive attitude of the project teachers was undoubtedly the result of the availability of extra facilities. However, it should be added that. at the start of the project, departments were selected on the basis of the existing positive attitudes of the teachers. The selection criterion is a probable second source of influence on the attitude data collected during the third project year. The differences in attitude towards computers between project teachers and not-involved teachers formed a source of concern. The depth-first approach was beginning to induce a sense of distance between the teachers enjoying substantial facilities for exploring the use of computers in the classroom and those who did not have them. The privileged teachers had a substantial advantage in comparison to the remaining teachers who easily developed feelings of jealousy not only towards the privileged colleagues but, in general, towards computers as an educational tool. This distancing tendency could be felt in the communication between project teachers and remaining teachers, who often ascribed the positive feelings of the project teachers to the available facilities instead of the experienced enrichment of computers.

Since the teachers and the research team considered this distancing tendency as a disadvantage and a positive barrier against further use of educational technology throughout the school, it was decided to reduce the facilities of the project departments (no further support from subject-matter specialists and 5 instead of 6 released hours per department) and to invite three new departments to join the project, but with restricted facilities ( 2 released hours per department). This progressive broadening continued during the fifth, final, project year.

\section{The breadth-first period}

During the breadth-first period six new departments were invited to join the project, three in the fourth project year and three in the fifth project year. The six new departments received considerably less facilities than the old departments at the start of the project: 2 released hours and incidental support from the co-ordinators and system managers. The researchers did support the three departments starting in the fourth project year, but did not provide active guidance to the departments starting in the fifth project year. Instead, the teachers of the three latest-engaged departments were interviewed three times during their first year of active involvement. The interview dealt with: (a) exploration of software, (b) planning of experimental lessons. (c) involvement of other colleagues within the departments, and (d) long-term planning (at the end of the school year). The interview data were passed to the co-ordinators to be used in further contacts with the departments.

The six "old" departments continued independently with 4 released hours per department and support from co-ordinators and researchers. The number of lessons in the computer labs still increased from year to year. Table 2 presents an overview of the percentages of teaching periods in the two computer labs during the last 4 project years.

It appears that the six "old" departments attained a level of continual and consistent use by the end of the project. A number of teachers decided not to continue with new applications to be

\begin{tabular}{|c|c|c|c|c|c|}
\hline & Year 2 & Year 3 & Year 4 & Year 5 & $\begin{array}{c}\text { Year } 6 \\
\text { Semester } 1\end{array}$ \\
\hline Geography & 6.5 & 8.0 & 6.0 & 5.6 & 3.5 \\
\hline Economics & 5.3 & 4.1 & 4.4 & 7.1 & 3.9 \\
\hline English Language & 3.5 & 3.1 & 4.8 & 5.1 & 2.4 \\
\hline Physics & - & 1.2 & 2.4 & 1.7 & 2.2 \\
\hline Dutch Language & 5.4 & 10.8 & 11.4 & 11.5 & 11.2 \\
\hline Mathematics & 6.8 & 8.1 & 8.6 & 9.2 & 5.7 \\
\hline New departments (Year 4) & $\ldots$ & - & 1.9 & 5.4 & 6.8 \\
\hline New departments (Year 5) & $\ldots$ & $\ldots$. & - & 10 & 11.7 \\
\hline Computer science & 17.3 & 17.6 & 16.0 & 17.8 & 17.0 \\
\hline Other departments & - & - & 3.1 & 3.0 & 7.9 \\
\hline Total occupancy rate & 44.8 & 52.9 & 58.6 & 67.4 & 72.2 \\
\hline Total number of lessons & 861 & 935 & 738 & 1133 & 520 \\
\hline
\end{tabular}


realized in the classroom, but, instead, to promote the use of computers in their disciplines by contributing to workshops outside the school and accepting part-time job offers by educational service institutes which provide advice and support to teachers and schools. During the breadthfirst period, general facilities were continued. In-service workshops were prepared. Apart from that, teachers received advice and supporting materials on a one-to-one basis.

The questionnaire on computer-related attitudes was administered on two occasions after the shift from depth-first to breadth-first had taken place. Table 1 shows a clear trend towards consensus on the potential of computers. The differences between project-teachers and remaining teachers were significant in $1989(F=32.4, P<0.01)$ and $1991(F=6.9, P<0.05)$. In 1992 this difference disappeared. Comparing the attitudes over the 3 years we can conclude that the positive attitude of the project teachers did not significantly decline, whereas the attitude of the remaining teachers significantly moved in upward direction. This is exactly what we hoped to realize by the shift from depth-first to breadth-first.

\section{CONCLUSIONS}

Returning to the research and implementation concerns explained in the Introduction, the question arises whether the implementation strategy of progressive broadening sufficiently met the constraints which characterize a technology-enriched school project. Our conclusions are based on the experiences in the West school, since it was this school in which the progressive broadening implementation strategy was developed and applied.

What were the critical success factors of the progressive broadening strategy?

The first factor was the creation of an avant-garde of teachers by concentrating the available facilities in a few departments. Teachers in these pioneering departments used the facilities to develop a number of tangible products of appropriate use of computers in education. Something interesting was happening here and everybody in the school noticed that.

The second factor was the encouragement and inspiration the remaining teachers received from the avant-garde to follow their examples and also to make a start with using computers in the classroom. The successes of the pioneers have, to a considerable extent, reduced the hesitations of the remaining teachers.

The third success factor of our implementation strategy was the close collaboration between teachers and researchers. In some departments, teams of teachers within the same discipline (usually two) and researchers (sometimes accompanied by subject-matter experts) were formed to develop, implement and evaluate new applications. Consensus was pursued during all stages of the implementation process. This implies that the research activities of the project could not be completely defined and planned at the outset. On the contrary, from the very start of the project the initiative to explore and start possible computer applications was assigned to the teachers. The researchers' task was to support and guide the activities of the team and to ensure that at least two applications were tried out in the classroom during the first year of the project. The teachers showed signs of discomfort during the first phase of the project. They expected the researchers to take the initiative and often asked for concrete plans. However, after this period (for some departments the entire first school-year of the project), the teachers were accustomed to the idea that they had to take the lead in the implementation process.

We contend that close collaboration between teachers and researchers is indispensable in innovation projects like the Dutch TES project. First, teachers bear the ultimate responsibility for all processes in the classroom. Therefore, they must agree and endorse the way computers are integrated in their teaching activities and in the learning activities of the students. Secondly, if teachers do not feel responsible for and in charge of the entire innovation process, they cannot be expected to continue after the TES project has come to its end [2]. As it is among the project's objectives to create a stable situation of continuous use of information technology in all education processes in the project schools, it is of great importance that the teachers consider themselves as the principal change agents.

Returning to Fullan's criteria for teacher involvement [5] the question can now be addressed as to whether, in the West school of the Dutch TES project, the teachers had the opportunity to apply Fullan's three criteria of the existence of a need, the availability of a clear plan of action, and the 
positive balance between costs and benefits. As far as the avant-garde teachers are concerned the conclusion seems warranted that the preconditions in terms of Fullan's three criteria were not favourable. At the outset of the project, teachers were invited to join the project on the basis of their enthusiastic response on the project's proposals. However, as most of them confirmed during interviews in the course of the project, they took a fairly neutral stance with regard to the expected value of computers in education. Secondly, clear plans were not available at the start of the project. The research team and the co-ordinators in the school asked the teachers to develop at least one computer application in the classroom during the first year and offered the facilities described above. So the teachers were supposed to take the initiative. Many of them felt rather uneasy about this division of labour and responsibilities between teachers and researchers, and they needed some time to adopt their role as innovators. However, after this period of habituation they took the initiative for developing and implementing experimental teaching units with the computer as an aid. In the meantime, they were heavily supported by facilities such as released-time, in-service training and the assistance of the research and production team in each department. Thirdly, the balance between personal costs (time, effort) and benefits (new skills and competences) had not been stabilized at the outset of the project. Again, the prospects were rather unclear.

The conclusion must be that the avant-garde teachers did not use Fullan's three criteria for teacher involvement as a ground for the decision to join the project. Which other motives might have led them at that time? Perhaps, there was a general positive attitude towards the main objective of the project: creating a situation of intensive use of information technology which might put the project schools ahead of the other schools in this respect. The existence of such an attractive leading principle, albeit rather vague and unclear in its consequences for the work load of the individual teachers, may have seduced them to embark on the project.

As far as the second group of teachers is concerned, who joined the project during the second stage of progressive broadening, the circumstances were much more appropriate to apply Fullan's criteria and to arrive at a balanced decision to join the project. The benefits for the students of introducing computers were made visible by the exemplary teaching and learning activities in the avant-garde departments. The implementation plan was clearer since researchers and co-ordinators regularly discussed an action plan dealing with five activities: (a) explorations of new software, (b) improving knowledge and skills, (c) developing an application in the classroom, (d) gaining the interest of fellow teachers within the department, and (e) after the first period of exploration, developing a long-term plan for integrating computers in the existing curriculum. For the follower teachers, the costs and benefits were easier to calculate and balance since the avant-garde teachers had already accumulated a considerable experience in both sides of the balance.

So, the follower teachers could use the experiences and results of the avant-garde teachers and departments to arrive at a decision to join the project. For these teachers who might have belonged to other categories than the developers/participators, Fullan's criteria may have served as a ground for submitting a proposal to join the project.

To summarize our conclusions, based on the experiences in the West school of the Dutch TES project, the implementation strategy of progressive broadening in which teachers, researchers and subject-matter experts closely collaborate, is a sound basis for initiating a process of educational change. At the start of the project, a convincing leading principle is necessary to gain the interest of a restricted amount of teachers, determined to actively contribute to the process of educational change. These teachers should be provided with considerable support and facilities. They have to create the preconditions on the hasis of which a larger group of teachers may decide to join the project in the second stage of progressive broadening. Finally, this implementation strategy may produce two distinct outcomes: well-established improvements in the teaching and learning processes, and an increased amount of teachers who see themselves as the principal responsible agents in the process of educational change.

\section{REFERENCES}

1. Collis B. and Carleer G. (Eds), Technology-enriched Schools. Nine Case Studies with Reflections. ISTE, Eugene, Ore (1992).

2. Berman P. and McLaughlin M., Implementation of educational innovation. Educl Forum 40, 345-370 (1976). 
3. Tikunoff W. and Ward B., Interactive research on teaching: an overview of the strategy. Far West Laboratory, San Francisco (1979).

4. Sarason S., The Culture of School and the Problem of Change. Allyn \& Bacon, Boston, Mass. (1971).

5. Fullan M., The Meaning of Educational Change. Teachers College Press, New York (1982).

6. Timmer J., Koplopers. Een studie naar het gebruik van educatieve software in het voortgezet onderwijs. (The avant-garde. A study into the use of educational software in secondary education.) S.C.O., Amsterdam (1991).

7. Fullan M., Miles M. and Taylor G., Organization development in schools: the state of the art. Rev. Educl Res. 50, 121-184 (1980).

8. Louis K. and Rosenblum S., Linking $R \& D$ with Schools: A Program and its Implications for Dissemination. National Institute of Education, Wash. (1981).

9. Moonen J. and Beishuizen J. J., Technology-enriched schools in the Netherlands. In Technology-enriched Schools. Nine Case Studies with Reflections (Edited by Collis B. and Carleer G.), pp. 67-77. ISTE, Eugene, Ore. (1992).

10. Rosenblum S. and Louis K., Stability and Change: Innovation in an Educational Context. ABT Associates, Cambridge, Mass. (1979).

11. Loucks S. F. and Hall G. F., Implementing Innovations in Schools: a Concerns-based Approach. The University of Texas, Research and Development Center for Teacher Education, Austin, Tex. (1979).

12. Moonen J. F. M. M., Involvement and information: 15 challenges for computers in education. Educl Technol. 29, 7-11 (1989).

13. Van den Berg R. and Vandenberghe R., Onderwijsinnovatie in verschuivend perspectief. (Educational innovation in a changing perspective.) Zwijsen B. V., Tilburg (1981).

14. Beishuizen J. J., Studying a complex knowledge domain by exploration or explanation. J. Comput. Assisted Learning 8, 104-117 (1992).

15. Beishuizen J. J., Felix E. J. H. M. and Visch E., Implementation: breadth-first or depth-first? In The Eighth International Conference on Technology and Education (Edited by McKey G. and Trueman D.). Toronto, Canada (1991).

16. Spek H., Een grafiekenprogramma in de wiskundeles; met als voorbeeld VUGRAFIEK. (A graphics program to enrich mathematics education.) PRINT/VO Reeks Computers in de schoolpaktijk, nr 1. CPS, Hoevelaken (1990).

17. Visch E., Make ends meet with a spreadsheet. In Computers in Education. Proceedings IFIP Sth World Conference on Computers in Education (Edited by McDougall A. and Dowling C.). North Holland, Amsterdam (1990).

18. Bouman T. K., Wolters F. J. M. and Wolters-Hoff G. H., Een schaal om attitudes tegenover computers te meten. (An inventory to assess attitudes towards computers.) Ned. Tijdschr. Psychol. 44, 288-292 (1989). 